\title{
Food insecurity as a determinant of international migration: evidence from Sub-Saharan Africa
}

\author{
Ahmad Sadiddin ${ }^{1} \cdot$ Andrea Cattaneo $^{1} \cdot$ Marinella Cirillo $^{1} \cdot$ Meghan Miller $^{1}$
}

Received: 19 October 2018 / Accepted: 23 April 2019 /Published online: 27 June 2019

(C) FAO 2019

\begin{abstract}
In this paper, we examined how food insecurity can affect international migration aspirations and subsequent actions taken in preparation to move internationally from Sub-Saharan Africa. Drawing on a conceptual framework of the determinants of migration, we developed a three-stage regression model and tested it using data from the 2014 Gallup World Poll. The results indicate that multiple determinants play different roles in the migration decision process, which is characterized by aspirations, planning and final decision to migrate. Specifically, food insecurity is an important determinant of both the desire and the decision to migrate: food insecurity raises the probability of desiring to migrate internationally, with the probability of the desire increasing along with the severity of food insecurity. However, the probability of actually deciding to migrate internationally decreased as food insecurity worsened. These findings are in line with migration literature stating that the very poor, despite wishing to migrate, face tremendous constraints in transforming this desire into concrete decisions. Our results suggest that removing or reducing constraints to migration will benefit the poorest/most food insecure and highlight the need for an increased and effective coordination between food security and international migration policy agendas.
\end{abstract}

Keywords Migration aspiration · Migration decisions $\cdot$ Migration barriers $\cdot$ Food insecurity $\cdot$ Sub-Saharan Africa

\section{Introduction}

International migration, defined as movement of people across national borders with the intention of staying in the host state, has been increasing and, in parallel, has been receiving greater attention from economists and policy makers. Food insecurity, defined as the lack of reliable access to sufficient quantities of nutritious food, has been increasing in recent years as well (FAO et al. 2017, 2018). Recently, there has been a growing number of studies on the links between migration and food security, mostly focusing on the impacts of the former on the latter. Despite variation in findings, migration is widely acknowledged as having mostly positive impacts on food security and nutrition of household members left behind, owing to remittances from migrants (Zezza et al. 2011; Crush 2012). The importance of remittances in promoting food security was

Ahmad Sadiddin

ahmad.sadiddin@fao.org

1 Food and Agriculture Organization of the United Nations, Rome, Italy underlined by the World Bank's Africa Migration Project, which found that a large proportion of remittances was spent on food in Sub-Saharan Africa (Plaza et al. 2011).

Food insecurity is also acknowledged as a determinant of migration. A recent study of eight developing countries suggested that food insecurity - stemming from the impacts of adverse climatic factors on agricultural productivity - can drive migration (Warner and Afifi 2014). Similar results were found in a case study in Ghana, where migration was revealed to be a typical livelihood strategy used by many rural households to cope with adverse weather conditions that reduce farm productivity and threaten food security (RademacherSchulz et al. 2014). Another study from El Salvador, Guatemala and Honduras, where nearly half of all households interviewed in 2016 were food insecure, confirmed clear links among food insecurity, adverse climatic events and migration (IADB et al. 2017).

However, very few studies directly treat food insecurity as a determinant of migration, specifically using a measure of individual-level food security status to investigate its impacts on the individual-level migration decision process. The paucity of this type of study is clearly due to the unavailability of the type of data needed to conduct such analyses. A relevant 
development came in 2014, however, when the Gallup World Poll (GWP) began collecting data on food insecurity at the individual level, as part of the Food and Agriculture Organization's (FAO) Voices of the Hungry Project, which developed an experiential measure of food insecurity called the Food Insecurity Experience Scale (FIES). FIES data have been collected annually through the GWP since then for approximately 150 countries. In addition to the FIES, the GWP collects information on people's lifestyle, attitudes and beliefs, as well as characteristics of individuals and households, providing an unprecedented opportunity to study the causes and consequences of food insecurity.

Our study builds on the sole investigation of this kind, to the best of our knowledge, that used both FIES data and other migration-related variables from the GWP. Smith and Floro (2017) examined how individuals' food insecurity status related to both the intention (desire) ${ }^{1}$ to migrate and the eventual decision to do so in a global sample of low- and middle-income countries, while additionally considering how the relationship varied by gender. Their findings revealed a positive relationship between the severity of food insecurity and the intention/ desire to migrate, while an inverse association was found between food insecurity and the decision to move. These trends were found to differ significantly between men and women. Our approach differs from that of Smith and Floro in two main regards. First, while they ran a global analysis, we focus only on Sub-Saharan Africa, the region with the highest prevalence of food insecurity (FAO et al. 2018). Second, we considered in our analysis the full migration decision process as measured by GWP surveys, which entails three stages. In addition to international migration desire and decision, we analyzed the determinants of migration planning as an intermediary stage in the decision process.

This paper examines how individual-level food security status can affect each of the three stages of the migration decision process. We analyzed GWP data on food insecurity (using the FIES), international migration, and individual characteristics, in addition to other relevant macro-level indicators external to the Gallup dataset. The migration process was captured through three sequential migration-related questions: The first question captures the respondent's desire to move to another country, while the second explores plans to migrate internationally in the following 12 months, and the third inquires whether any preparations have been taken for the move. We investigated the relationship between each of these three dependent variables, respectively, and food insecurity status, controlling for individual and household characteristics

\footnotetext{
${ }^{1}$ Smith and Floro use the term "intention" to refer to what we prefer to call "desire," as this term reflects more closely the spirit of the associated survey question, in our opinion.
}

as well as countries' level of development and whether they were in a protracted crisis, factors that the existing migration literature has identified as important determinants of the migration decision process.

Due to data constraints, most of the available evidence on individual variation in migration choice uses representative samples from within particular countries and rarely provides any comparative analysis of micro-level determinants of emigration across different countries. Therefore, one novel aspect of our analysis is that it provides a regional picture of the relationship between food security status and the steps of the migration decision process. The narrowed geographical scope of our paper allows for a detailed consideration of a region disproportionately affected by severe food insecurity and protracted crises. $^{2}$

Examining food insecurity as a determinant of migration is becoming increasingly relevant as the number of international migrants increases, especially those migrating for economic reasons (FAO 2018), and with the rise in the global number of undernourished people (FAO et al. 2017, 2018). It can provide valuable information to governments and relevant international organizations on how to meet their commitments to the Sustainable Development Goals (SDGs), where achieving zero hunger by 2030 is a high priority. While food insecurity creates the incentive to migrate in search of better opportunities, the more food insecure proportion of the population generally come from the poorer segments of a society, and may therefore face prohibitive economic constraints to moving. Therefore, in an attempt to address food insecurity, policies may need to consider migration as an increasingly important livelihood strategy, and a potentially effective tool to improve food security.

The remainder of the paper proceeds as follows. In the second section, we present a conceptual framework that details the theoretical foundations for our empirical analysis. In the third section, we present a summary description of the data used in the analysis. The fourth section presents the econometric model we used to examine the role of individual food insecurity status in the migration decision process, which is composed of three consecutive stages: expression of migration desire and the subsequent planning and preparations required to undertake an international move. The model controls for a set of variables that are deemed important determinants of migration and considers cross-country variation. The fifth section is devoted to presenting the results and discussing their robustness through a series of sensitivity tests. The last section discusses some policy implications of the findings and concludes the paper.

\footnotetext{
${ }^{2}$ According to FAO et al. (2017), there are currently 19 countries in protracted crisis situations, 8 of which are in Sub-Saharan Africa.
} 


\section{Conceptual framework for determinants of international migration}

Our conceptual framework relies on the large body of literature describing the determinants of international migration, according to which the decision to move is a form of human capital investment (Schultz 1961; Sjaastad 1962; Clemens 2011). In making their decision, individuals compare the perceived differences in the expected utility of living or working in two geographical locations, net of the costs. Hence, both aggregate and microeconomic factors affect the net benefits of migration and thus affect the decision process.

Evidence on cross-country variation in emigration rates show that the latter significantly depend on differences in development levels across countries, the availability of diaspora networks, and changes in the supply of legal migration opportunities (Mayda 2010; Ortega and Peri 2013; Docquier et al. 2014). By using census data on international migration stocks from a large set of countries worldwide, Clemens (2014) showed that there is a marked inverted-U relationship between economic development at origin and emigration rates. Likewise, this inverted-U relationship also applies to individuals and households within each country. Thus, for countries at every level of development, it is generally those individuals who are neither very rich nor very poor (by the standards of their own countries) who are more likely to desire to migrate and to be able to do so. In other words, although the very poor may want to migrate in order to escape poverty by looking for better opportunities elsewhere, they may face insurmountable obstacles to doing so. This is especially the case when international rather than internal migration within a country is considered, as moving to another country is costlier and implies higher risks that the poorest may not be able to undertake (FAO 2018).

In addition, it has been shown that migrants are a selfselected sample of the population. They differ from nonmigrants with respect to their personal characteristics (e.g. age, gender), skills, education and socio-economic background. This is because these individual characteristics affect the ability to bear migration costs and to reap the benefits in the future (Borjas 1987; Chiswick 1999; Chiquiar and Hanson 2005; Beine et al. 2011).

Drawing on the conceptual framework developed by FAO (2018), we consider that there are three broad categories of factors interacting to influence the migration decision process. Macro factors comprise economic, socio-political, and environmental conditions that create the fundamental incentive for migration, which we call migration desire. These macro determinants may have differing impacts on various social groups, according to gender, age, wealth, language, and personal considerations.

Nevertheless, the move from a migration desire to a migration decision by an individual is not immediate, but is largely governed by intermediate conditioning factors that either constrain or facilitate migration. These include the strength of of the individual's social network at home and abroad, the functioning of local institutions and markets, the cost of migrating and access to information, among others. For instance, the presence of strong social networks at the destination can help overcome bureaucratic procedures and obstacles, provide information and assist in finding housing and jobs.

These previous two sets of migration determinants are both, to a large extent, external to the actors. However, the decision to migrate or to stay is the consequence of people's agency and thus depends on personal factors, i.e. microdeterminants of migration, since no two potential migrants perceive macro structural factors or interact with the conditioning factors in the same way, as they have unique individual, household and even community capabilities and capacities. Therefore, age, gender, education and other personal factors matter, and when the decision to migrate is made collectively by the whole household, the characteristics of the household also matter, e.g. the number of children or youth, the gender composition and power distribution within the household. Based on how people are affected by intermediate factors, those desiring to migrate would proceed to migration planning or not, this being the intermediate step before the migration decision.

Figure 1 illustrates how macro determinants, intermediate conditioning factors and micro-factors interact, leading to the decision to migrate or to stay. A range of macro-factors creates the incentives to migrate. The intermediate conditioning factors act to increase or reduce the incentive or the ability to migrate, i.e. they either facilitate or constrain people's mobility, and so they together determine the costs of migration, which include financial, social, cultural and psychological costs. In the end, when people decide to migrate or to stay, they interact with the external factors, based on their individual and household characteristics, including, among others, age, gender, education level, wealth, employment status, household composition, and personal preferences.

The lower part of Fig. 1 links each of the three categories of determinants to an associated share of the population in question. The incentive to migrate due to the macro-factors is perceived by a share of the population (shown in dark green). But a smaller share of those desiring to migrate may consider migration happening in the near future (in turquoise) because they are facilitated, or at least not constrained, by the intermediate conditioning factors. Finally, only a subset of the people who would be able to migrate actually decide to do so, based on their individual or household characteristics (shown in light green).

The framework can also be extended to accommodate for external shocks that may have considerable implications for people's attitudes towards international migration. Political instability, conflicts, natural disasters or any type of protracted 
Macrofactors create incentives to migrate that may be restricted or eased by conditioning factors, but migration decisions are ultimately made by individuals and households.

\begin{tabular}{|c|c|c|}
\hline MACRO FACTORS & $\begin{array}{l}\text { Economic opportunities and well-being, socio- } \\
\text { political conditions }\end{array}$ & $\begin{array}{l}\text { - Demographics and environment } \\
\text { - Risk differences between economic } \\
\text { activities }\end{array}$ \\
\hline $\begin{array}{l}\text { INTERMEDIATE } \\
\text { CONDITIONING } \\
\text { FACTORS }\end{array}$ & $\begin{array}{l}\text { - Network \& diaspora } \\
\text { - Institutions \& laws } \\
\text { - Local factor market failures }\end{array}$ & $\begin{array}{l}\text { - Distance/moving costs } \\
\text { - Technology }\end{array}$ \\
\hline MICRO FACTORS & $\begin{array}{l}\text { - Personal characteristics and preferences: age, } \\
\text { gender, education, marital status, preferences. }\end{array}$ & $\begin{array}{l}\text { - Household characteristics: wealth, } \\
\text { religion, ethnicity, language }\end{array}$ \\
\hline
\end{tabular}

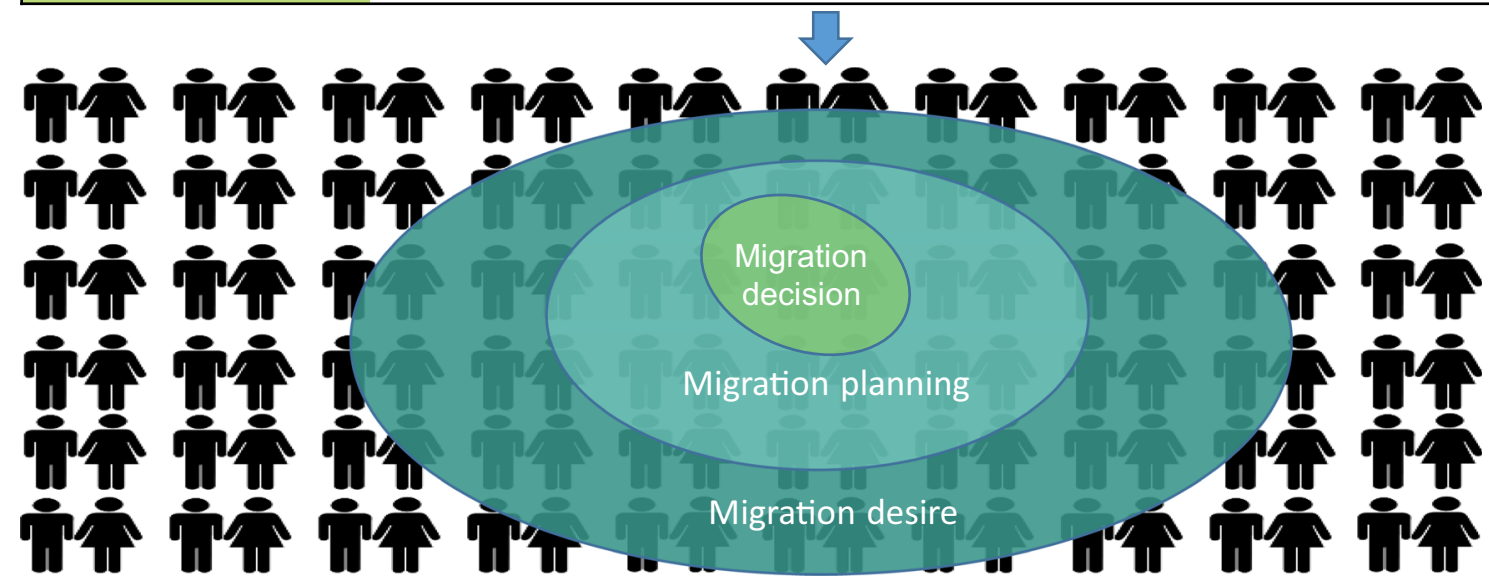

Only part of total population would have an incentive (desire), but a smaller portion would consider migration as a viable strategy (planning), but an even smaller portion would actually migrate (decision).

Fig. 1 Factors affecting the migration decision-making process. Source: adapted from FAO (2018)

crisis can worsen the socio-economic and even the security conditions in countries of origin. Such shocks, when they last for a relatively long period, affect not only the macro differentials between countries of origin and the potential destination countries, but they also cause modifications to the intermediate conditioning factors. As an example, crossing the borders become easier under armed conflicts due to efforts of humanitarian agencies and the establishment of institutions to deal with the crisis. In the end, the pools of potential migrants, depicted in the lower part of Fig. 1, become larger due to the impacts of the crisis on each set of determinants, and consequently migration outflows increase.

However, it should be emphasized that the various levels of migration determinants illustrated in Fig. 1 do not work in isolation from each other; rather, they work in combination, with their interactions depending on the context. The same determinant may play different roles depending on the phase of the decision process, for example individual and household characteristics may increase an individual's desire to migrate but constrain his or her ability to do so, depending on the macro and conditioning factors.

\section{Data and descriptive statistics}

As mentioned previously, the GWP collects data annually for approximately 150 countries on peoples' lifestyles, attitudes, beliefs, as well as characteristics of individuals and households, including their attitudes towards international migration. Since 2014, the Food Insecurity Experience Scale (FIES) survey module at the individual level has also been applied as part of the poll. In this paper, we analyze GWP data to assess the role of food insecurity (as measured through FIES) in the international migration process, controlling for individual and household characteristics in addition to other relevant macro-level indicators external to the Gallup dataset.

The international migration process is captured in the GWP through three sequential migration-related questions, which refer to permanent international migration. By international, we mean that the move is from one country to another, regardless of the distance between the two countries. By permanent, we exclude moves that are intended to be temporary, seasonal or circular, which are typical of intra-regional migration patterns observed in some parts of the World including Sub- 
Saharan Africa (Mercandalli and Losch 2017). The three sequential migration questions from the GWP are:

1- "Ideally, if you had the opportunity, would you like to move permanently to another country, or would you prefer to continue living in this country?" This question is asked of the full sample.

2- "Are you planning to move permanently to another country in the next 12 months, or not?" This question is asked only of those who answered "yes" to the previous one.

3- "Have you done any preparation for this move?" (Examples include buying an air-ticket, applying for a visa, or making other arrangements for the move). This question is asked of only those who answered "yes" to the previous two questions.

We consider the first question as investigative of the international migration desire, the first step of the migration decision process. The implicit assumption is, of course, that people will not decide to migrate unless they first desire to do so. The second question captures an important second step towards actual migration, since it focuses on planning for a move within a close and defined time-frame. We consider this question to represent international migration planning. As the third question concerns the specific arrangements made for the move, we consider it a proxy for an international migration decision, ${ }^{3}$ referring to a move that is likely to happen in the near future. These three variables are each binary and take the value of 1 if the individual answers yes; zero otherwise.

We investigated the relationship between each of these three dependent variables, respectively, and food insecurity status, controlling for individual and household characteristics as well as across-country variation caused by different levels of economic development and political conditions, such as the presence of protracted crises, and factors that the existing migration literature has identified as important determinants of the migration decision process.

The GWP surveys approximately 1000 individuals aged 15 years and older per year in each country. The randomly selected samples are nationally representative of the adult population and the survey covers the entire country (both rural and urban areas), except in the cases where safety or accessibility issues exist in certain areas. Face-to-face interviews are used in countries with less than $80 \%$ telephone coverage, and telephone interviews are conducted otherwise. A multi-stage

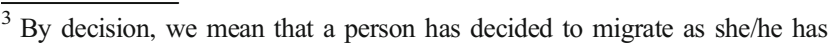
made preparations to implement the decision. However, we do not mean that actual migration has taken place as we do not have data on whether the decision has been successfully implemented or not. Therefore, people who decided to migrate in this paper cannot be equated with migrants who have actually moved from their areas of origins.
}

sampling design is used to select the individuals interviewed face-to-face, while a random-digit-dialing approach is used in telephone-interview countries. The GWP also takes steps to ensure comparability across countries; for example, education is categorized into three broad levels to be comparable across countries where educational systems differ. For the same purpose of global comparability, income is converted into International Dollars using the 2011 PPP (Purchasing Power Parity) estimates (Gallup 2018).

As introduced earlier, the FIES is a globally-validated experiential measure of food insecurity, developed by the FAO's Voices of the Hungry Project. FIES data are produced from binary (yes/no) responses to eight questions covering a range of behaviors and experiences associated with access to food. It is expected that more severely food insecure people will report having faced a greater number of these experiences over the previous 12 months than food secure or less severely food insecure people. Using standard thresholds, and according to their responses to the FIES questions, people are classified into groups indicating their food security status, commonly designated severely food insecure, moderately food insecure, mildly food insecure and food secure (FAO 2016).

The design of the FIES survey module is based on previous research revealing that the experience of food insecurity is characterized initially by uncertainty and worry regarding access to food, followed by changes in the quality of diet as the situation worsens. When the situation becomes severe, food consumption decreases in quantity, as portions are reduced and meals skipped, up to the point where a person may go an entire day or more without eating (Radimer et al. 1990, 1992; Radimer 2002). A review published in 2006 and covering studies derived from many countries in different regions of the world concluded that these experiential dimensions of worry, compromising diet quality, and reduced food quantity appear to be common across cultures and languages (Coates et al. 2006).

To validate the FIES data, the FAO uses an approach borrowed from Item Response Theory, specifically the one parameter logistic model known also as the Rasch Model (Rasch 1960), considering the individual's severity of food insecurity to be a latent trait (Nord et al. 2016). The observable conditions that are assumed to be caused by the latent trait are the basis of the FIES survey module. A scale of food insecurity severity (Rasch 1960) is estimated for each country, based on the patterns of responses received, with each question in the survey module, as well as each respondent surveyed, located along the same scale. When the FIES data pass a statistical test of fit to the Rasch model's assumptions (Rasch 1960), an individual's food security status can be determined by summing the affirmative responses (i.e., the "raw score"), which provides an ordinal measure of severity. However, 
because each application of the FIES module results in a unique scale, two individuals from different places with the same raw score may not, in fact, have a truly similar severity of food insecurity.

To achieve precise comparability of prevalence rates of food insecurity, application of the Rasch model produces the respondent parameter, which is the level of severity along a continuous scale that is associated with each raw score. Then, standard thresholds used to classify individuals into categories of food insecurity are mapped from a global reference scale onto the country's scale to place them on the same metric of severity, a process called "equating." Respondents are then assigned probabilistically to classes of food insecurity severity in order to calculate rates of food insecurity at different levels of severity.

In this paper, we recognize the importance of equating and the probabilistic approach for achieving comparable prevalence rates, yet have adopted the raw score cut-offs most closely approximating to the more precise thresholds along the continuous scale described above: raw scores $0-3=$ food secure to mild food insecurity, 4-6= moderate food insecurity, and $7-8=$ severe food insecurity. This decision was made for its improved interpretation of coefficients in regression models. Additionally, data from the Sub-Saharan African countries analyzed here have been previously validated and shown to pass the tests of adherence to the Rasch model. Furthermore, due to the wide distribution of "true" food insecurity severity estimated around respondents with raw score 1 (those who answered "yes" to only one out of the eight FIES questions), there is a high risk of misclassifying someone with this raw score as incorrectly either "food secure" or "mildly food insecure." Therefore, we have opted to combine these respondents at the less severe end of the scale as "food secure or mildy food insecure" (FAO 2016).

For this study, we used GWP data from 2014 for SubSaharan Africa. The choice of the 2014 wave was dictated by the objective of maximizing coverage in terms of variables of interest. In addition to covering more countries for the core variables of interest, i.e. FIES and international migration data, this year has also high coverage for the other control variables of interest, including gender, age, education, marital status, household size and composition, personal religious belief, social relations (network effect) and area of residence (rural or urban). Other socio-economic control variables included were personal income and employment status, as well as personal views on the quality of available services such as water, healthcare and education. For the complete list of these variables, detailed as they are in the GWP and with their summary descriptive statistics in the selected sample, see Table 1.

The original subset of 2014 data for Sub-Saharan Africa contained 36 countries and 36,044 individuals. Cases with missing data, "don't know," or "refused" to answer for any of the variables included in our model were omitted from the analysis. Owing to significant missing data (entire variables), Liberia, Sierra Leone, Somalia, and Botswana were dropped, leaving 32 countries in the analytical sample. It is also important to note that coverage issues were present for Madagascar, Mali, Somalia, Sudan, and South Sudan, meaning that estimates for these countries may not be nationally representative. The reduced dataset used for the analysis included 29,492 cases. In Table 1, the summary statistics are presented for the full analytical sample, for the share of respondents desiring to migrate, for the share of respondents planning to migrate, and for the share of respondents making preparations to leave (our proxy for a migration decision).

In the analytical sample, about $27.9 \%$ answered that they would move to another country if they had the opportunity. The share differs widely across countries in the sample, from $11.4 \%$ in Madagascar to $59 \%$ in the Democratic Republic of the Congo. Countries in our sample differed in various socio-economic and demographic indicators as well as in their policy and institutional settings, which created the fundamental incentives to migrate.

However, the share of those planning to migrate to another country in the following 12 months was much lower everywhere, amounting to only $5.3 \%$ in our entire sample, while the share of those who have begun preparations to move is no more than $1.5 \%$. This sharp decline is due to the complexity of the migration decision process, which entails a mix of individual and household considerations in addition to the intermediate conditioning factors and the macro-factors. As international migration is costly, in both economic and psychological terms, only smaller proportions of those desiring to migrate under ideal conditions would be able to overcome the constraints that impede them from actually moving.

Although this declining trend along the migration process is universal in our sample, the shares do not decline equally. For example, the Democratic Republic of the Congo has the highest share of those desiring to migrate in the full sample, but the highest share of planning (within those desiring to migrate) is observed in Togo $(40.7 \%)$, which comes sixth in terms of desire. By the same token, among those planning to migrate, the share of those deciding to migrate is highest in Cameroon $(75.0 \%)$, a country that comes twelfth in terms of desiring to migrate $(29.1 \%)$ and twenty-ninth in terms of planning to migrate $(10.3 \%)$. Based on our conceptual framework, these differences are explained not only by differences in individual and household characteristics within and among countries, but also by differing intermediate conditioning factors and macro differentials within and among countries.

Table 1 also shows an interesting trend in our core independent variable, food insecurity, in relation to the four 


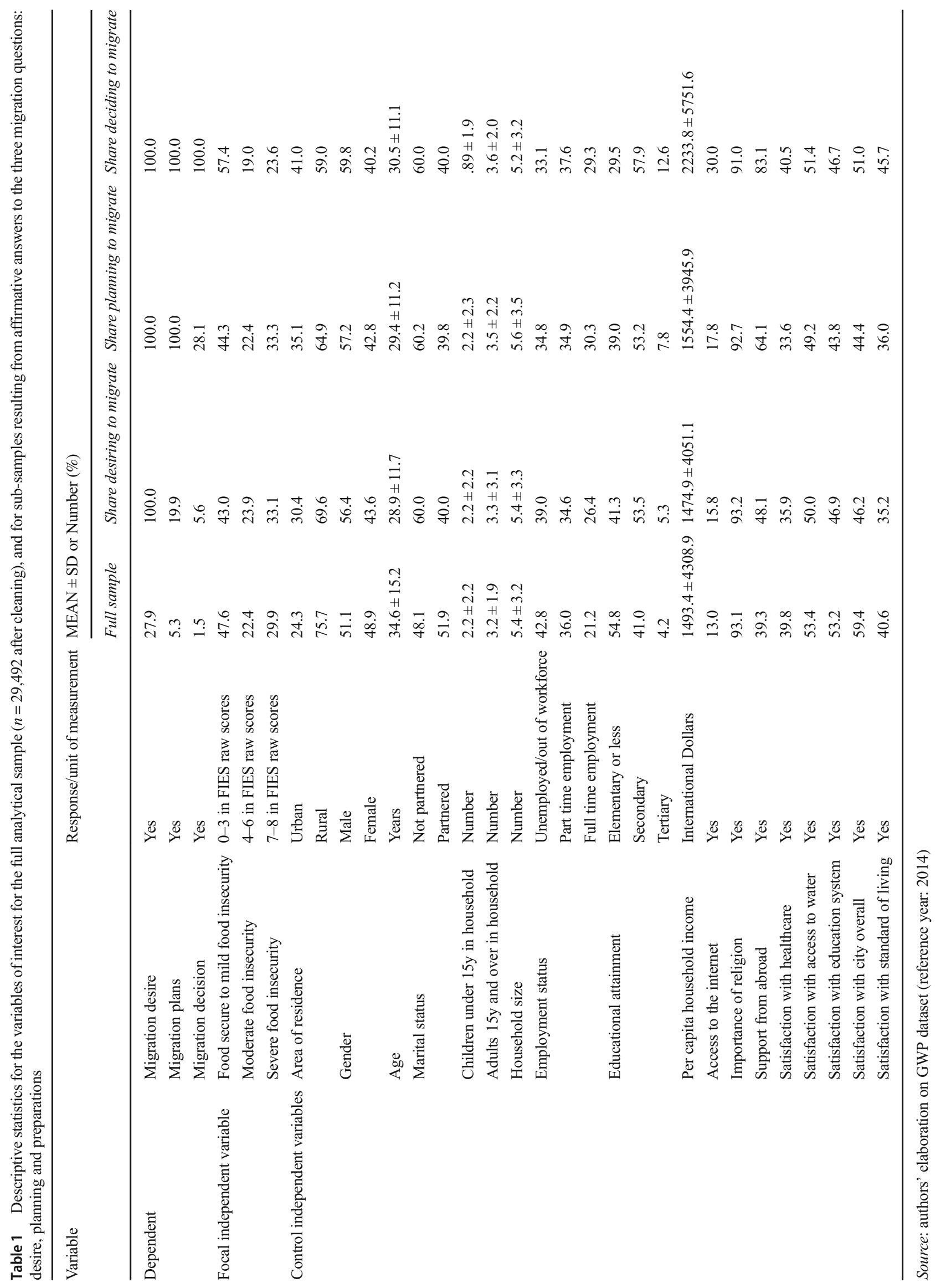


samples. Looking at the categories with severe (moderate) food insecurity, defined as FIES raw score of 7-8 (4-6) in the full sample, $29.9 \%$ (22.4\%) were severely (moderately) food insecure, but this proportion increased to $33.1 \%$ (23.9\%) among those desiring to migrate, highlighting the potential importance of food insecurity as a motivation to migrate towards better opportunities. Among those who have actually decided to migrate, the proportion of severely (moderately) food insecure dropped to $23.6 \%$ (19\%). In other words, when moving from the full sample to only those desiring to migrate, the proportion of food insecure goes up, but this proportion decreases noticeably if the sample is further restricted to those actually deciding to migrate. In this respect, the patterns observed in Table 1 are in line with our conceptual understanding: among those desiring to migrate, the "worse-off," are less able to shoulder the costs of an international move. The basic premise is that food insecurity should cause outmigration in search of better opportunities, but outmigration will only occur when potential migrants (those desiring to migrate) can overcome the constraints to migration and cover the associated costs. This leads us to the following proposition: high levels of food insecurity are expected to have a strong and positive impact on the desire to migrate. However, as high levels of food insecurity reflect economic hardship, their relationships to the final decisions (taking actual preparations to migrate) and on intermediate steps (planning to migrate) may be weaker.

The profile differs also in terms of other variables, when moving between the full sample and the sub-sets of those who desire and those who are planning. To highlight a few key differences (shown also in Table 1), while a higher proportion of males desire to migrate, this gender gap widens even further as respondents progress along the migration decision process, with $56.4 \%$ of those desiring to migrate, $57.2 \%$ of those planning, and $59.8 \%$ deciding to migrate being male. We also see that the profile of the sample changes according to area of residence, with the proportion of urban residents increasing along the migration decision process. Compared with $24.3 \%$ urban in the full sample, $41.0 \%$ of those deciding to migrate come from urban areas. A similar trend can be observed with regard to educational attainment: as the education level of the sub-sample of people deciding to migrate is markedly higher (12.6\% with tertiary levels) than in the full sample $(4.2 \%)$ or in preceding stages along the decision process. There is a strong increase in the proportion of people with support available abroad, as one moves along the stages towards a decision to migrate: $83.1 \%$ of those ultimately deciding to move have someone they can count on in another country, compared to only $39.3 \%$ in the full sample. Access to the internet is also seen to rise, as $30.0 \%$ of those deciding to migrate are able to access resources online, while only $13.0 \%$ of the full sample are.

\section{Methods: empirical operationalization of the migration decision process}

Based on the conceptual framework laid out in Section 2, combined with the data available as described in the previous section, we used three econometric equations to measure the impact of food insecurity status, as measured by FIES, on the international migration decision process. First, we consider the desire to migrate to be the first step of the process. Based on whether respondents desire to migrate or not, they will or will not be included in the following step, as the subsequent question on planning to migrate within the following 12 months is asked only to those desiring to migrate. The planning question captures an important step towards migration since it focuses on the presence of planning with a close and defined time-frame. Only the third question gets very close by referring to preparations for the move. This is why we consider it a proxy of the imminent international migration decision. ${ }^{4}$

Our principal hypothesis is that the level of food insecurity is central to people's attitudes towards migration. People may desire to migrate because they suffer from severe food insecurity or simply because they fear worsening of food security conditions due to factors that may be beyond their direct control. However, although food insecurity at the individual and household levels can be a strong incentive to migrate, we learn from the framework laid out above that it is far from being sufficient. As migration is costly and as those who suffer from severe food insecurity are found among the poorest, food insecure people may not be able to migrate due to lack of resources, both economic and otherwise, to cover migration costs and overcome other constraints.

People first desire or not desire to migrate. Once people do not desire to migrate they are excluded from the potential migrants' pool (people placed outside the ovals in Fig. 1), and by default they will not consider migration planning or preparations. Only those desiring to migrate in the first place will consider planning to do so within a given time-frame. By the same token, once people plan to migrate, they may later decide to go through with the plan, or not. Consequently, when studying what drives the migration decision, only those planning to migrate should be considered. In brief, the operationalization of the conceptual framework requires using three econometric equations, where the sub-samples examined in the second and the third equations are the results of responses provided to the first and the second questions, respectively. The independent variables in the three equations to

\footnotetext{
${ }^{4}$ By decision, we mean that a person has decided to migrate as she/he has made preparations to implement the decision. However, we do not mean that actual migration has taken place as we do not have data on whether the decision has been successfully implemented or not. So people who decided to migrate in this paper cannot be equated with migrants who have already moved from their areas of origins.
} 
be estimated are the same; they only differ in the dependent variable and the sample of data they analyze.

Therefore, we examined the role of food insecurity in international migration desire and subsequent migration planning and decision, of both women and men from 32 developing countries located in Sub-Saharan Africa, the region where the prevalence of food insecurity is the highest globally and has worsened in recent years (FAO et al. 2017). We estimate the following three equations independently of one another, where the three binary variables are regressed on the individual food insecurity status controlling for a set of variables that are widely acknowledged in the literature to affect the migration decision process.

$$
\begin{gathered}
M . D_{i c}=\beta 0+\beta 1 F S_{i c}+\beta 2 X_{i c}+\beta 3 V_{c}+e_{i c} \\
M . P_{i c}=\alpha 0+\alpha 1 F S_{i c}+\alpha 2 X_{i c}+\alpha 3 V_{c}+e_{i c} \\
\quad \text { when } M . D_{i c}=1 \\
M . D e c_{i c}=\gamma 0+\gamma 1 F S_{i c}+\gamma 2 X_{i c}+\gamma 3 V_{c}+e_{i c} \\
\text { when } M . P_{i c}=1
\end{gathered}
$$

Where, M.D. $D_{i c}, M . P_{i c}$ and $M . D e c_{i c}$ represent international migration desire, international migration planning and international migration decision, respectively of an individual $i$ who lives in country $c . F S_{i c}$ represents the food insecurity status taken from the FIES.

$X_{i c}$ represents the individual characteristics of the individual $i$ in country $c$, while $V_{c}$ indicates the macro variables that differ by country, represented by dummy variables per country. Regressors included in $X_{i c}$ are individual socio-economic and demographic characteristics such as gender, age, age squared, ${ }^{5}$ education, marital status, number of children in the household and household size, the importance of religiosity, whether the individual has a friend or relative living overseas (network abroad) and area of residence (rural or urban). Other socio-economic controls included personal income (log of income in International Dollars as reported by GWP) and employment status. To account for people's perceptions of the quality of available services, we used a series of questions asking about whether respondents are satisfied or not regarding local education and healthcare systems, standard of living, access to water, and city or area of residence. For a summary description of the variables the data of which are taken from GWP, see Table 1 above.

The three equations were estimated with standard errors clustered at the country level by means of logit regression techniques, using country fixed effects to account for any country-specific differences that were not observed.

\footnotetext{
${ }^{5}$ We include age-squared as a regressor in addition to age to account for the non-linear relationship between age and migration. This is because migration literature has already established that younger people are more likely to migrate than older people.
}

\section{Results and sensitivity analysis}

The regression results, as shown in Table 2, which show the results of the regressions for migration desire, migration planning and migration decision, confirm that food insecurity is a significant determinant of the decision process of international migration in Sub-Saharan Africa. Results given for migration desire are average marginal effects estimated by regressing the migration desire binary-choice variable on the independent variables using the full sample data. However, the results for migration planning (migration decision) are conditional average marginal effects estimated by regressing the migration planning (migration decision) binary-choice variable on the independent variables, using the sub-sample of those who answered "yes" to the question of migration desire (using the sub-sample of those who answered "yes" to the questions of migration desire and migration planning).

We performed a series of sensitivity tests to evaluate the robustness of the results, examining the possible impact of various macro-level factors and shocks on the relationship between food insecurity and the migration decision process. We found that the relationship between food insecurity and migration variables was robust. The magnitude and significance of the food insecurity coefficients remained unchanged. For details on the sensitivity analysis, refer to Appendix 1 . We also tested for multi-collinearity among the explanatory variables. Although age and age-squared seemed to have high degrees of multi-collinearity in the full sample, they did not affect the robustness of the results. For details of the multicollinearity tests, refer to Appendix 2.

\subsection{Migration desire}

The results in column 1 suggest that food insecurity has a statistically significant and positive impact on migration desire. The food insecurity variable is associated with a significant increase in the probability of migration desire as the magnitude of the marginal effect increases with the severity of food insecurity. In other words, having moderate food insecurity increases the probability of desiring to migrate by $3.9 \%$ compared to those who are food secure or are only mildly food insecure. Furthermore, the probability of desiring to migrate increases to $5.2 \%$ for people experiencing severe food insecurity. These results indicate that greater severity of food insecurity is one of the key push factors in Sub-Saharan Africa that leads to increased desire to migrate internationally in search of better economic opportunities.

We also found evidence that area of residence was significantly associated with the desire to migrate internationally. Being a rural resident decreases the probability of desiring to migrate by $5 \%$ compared to an urban resident. This can be explained by the fact that generally rural people are less aware of opportunities in other countries. In addition, many rural 
Table 2 Average marginal effects and conditional average marginal effects from three binary-choice econometric equations

\begin{tabular}{|c|c|c|c|}
\hline Variables & Migration desire & Migration planning & Migration decision \\
\hline Moderate Food insecurity & $\begin{array}{l}0.039 * * * * \\
(-0.050)\end{array}$ & $\begin{array}{l}-0.013 \\
(-0.090)\end{array}$ & $\begin{array}{l}-0.069 * * \\
(-0.200)\end{array}$ \\
\hline Severe Food insecurity & $\begin{array}{l}0.052 * * * * \\
(-0.050)\end{array}$ & $\begin{array}{l}0.017 \\
(-0.090)\end{array}$ & $\begin{array}{l}-0.096^{* * *} \\
(-0.20)\end{array}$ \\
\hline Rural area & $\begin{array}{l}-0.050 * * * * \\
(-0.050)\end{array}$ & $\begin{array}{l}-0.028 * * \\
(-0.070)\end{array}$ & $\begin{array}{l}-0.020 \\
(-0.100)\end{array}$ \\
\hline Age & $\begin{array}{l}-0.004 * * * \\
(-0.009)\end{array}$ & $\begin{array}{l}0.007 * * * * \\
(-0.010)\end{array}$ & $\begin{array}{l}0.003 * * \\
(-0.007)\end{array}$ \\
\hline Age squared & $\begin{array}{l}-0.000 \\
(-0.000)\end{array}$ & $\begin{array}{l}-0.000 * * * * \\
(-0.000)\end{array}$ & $\begin{array}{l}0.000 \\
(-0.000)\end{array}$ \\
\hline Gender male & $\begin{array}{l}0.050 * * * * \\
(-0.040)\end{array}$ & $\begin{array}{l}-0.010 \\
(-0.060)\end{array}$ & $\begin{array}{l}0.017 \\
(-0.100)\end{array}$ \\
\hline Log household income & $\begin{array}{l}0.020 * * * * \\
(-0.040)\end{array}$ & $\begin{array}{l}-0.002 \\
(-0.080)\end{array}$ & $\begin{array}{l}0.002 \\
(-0.200)\end{array}$ \\
\hline Married or domestic partner & $\begin{array}{l}-0.049 \text { ***** } \\
(-0.040)\end{array}$ & $\begin{array}{l}-0.016 \\
(-0.080)\end{array}$ & $\begin{array}{l}0.010 \\
(-0.200)\end{array}$ \\
\hline Employed part time & $\begin{array}{l}0.020 * * \\
(-0.050)\end{array}$ & $\begin{array}{l}0.020 \\
(-0.080)\end{array}$ & $\begin{array}{l}0.020 \\
(-0.200)\end{array}$ \\
\hline Employed full time & $\begin{array}{l}0.059 * * * * \\
(-0.050)\end{array}$ & $\begin{array}{l}0.038 * * * \\
(-0.080)\end{array}$ & $\begin{array}{l}0.008 \\
(-0.200)\end{array}$ \\
\hline Number of children & $\begin{array}{l}-0.002 \\
(-0.010)\end{array}$ & $\begin{array}{l}0.020 \\
(-0.090)\end{array}$ & $\begin{array}{l}0.050 \\
(-0.200)\end{array}$ \\
\hline Number of adults & $\begin{array}{l}0.003 \\
(-0.050)\end{array}$ & $\begin{array}{l}0.002 \\
(-0.050)\end{array}$ & $\begin{array}{l}-0.007 \\
(-0.100)\end{array}$ \\
\hline Household size & $\begin{array}{l}0.005 * * * * \\
(-0.007)\end{array}$ & $\begin{array}{l}0.002 \\
(-0.010)\end{array}$ & $\begin{array}{l}0.001 \\
(-0.030)\end{array}$ \\
\hline Secondary education & $\begin{array}{l}0.059 * * * * \\
(-0.040)\end{array}$ & $\begin{array}{l}0.021^{*} \\
(-0.080)\end{array}$ & $\begin{array}{l}0.019 \\
(-0.200)\end{array}$ \\
\hline Post-secondary education & $\begin{array}{l}0.079 * * * * \\
(-0.100)\end{array}$ & $\begin{array}{l}0.056^{* *} \\
(-0.140)\end{array}$ & $\begin{array}{l}0.080 \\
(-0.300)\end{array}$ \\
\hline Importance of religion & $\begin{array}{l}-0.008 \\
(-0.070)\end{array}$ & $\begin{array}{l}-0.013 \\
(-0.130)\end{array}$ & $\begin{array}{l}-0.075 \\
(-0.200)\end{array}$ \\
\hline Support from abroad & $\begin{array}{l}0.102 * * * * \\
(-0.040)\end{array}$ & $\begin{array}{l}0.120 * * * * \\
(-0.080)\end{array}$ & $\begin{array}{l}0.190 * * * * \\
(-0.200)\end{array}$ \\
\hline Internet access & $\begin{array}{l}0.027 * * \\
(-0.072)\end{array}$ & $\begin{array}{l}-0.003 \\
(-0.100)\end{array}$ & $\begin{array}{l}-0.026 \\
(-0.200)\end{array}$ \\
\hline Satisfaction with education system & $\begin{array}{l}-0.021 * * * \\
(-0.003)\end{array}$ & $\begin{array}{l}-0.018^{*} \\
(-0.070)\end{array}$ & $\begin{array}{l}-0.012 \\
(-0.100)\end{array}$ \\
\hline Satisfaction with access to water & $\begin{array}{l}-0.010 \\
(-0.040)\end{array}$ & $\begin{array}{l}0.001 \\
(-0.070)\end{array}$ & $\begin{array}{l}0.007 \\
(-0.100)\end{array}$ \\
\hline Overall satisfaction with city or area of residence & $\begin{array}{l}-0.095 * * * * \\
(-0.040)\end{array}$ & $\begin{array}{l}-0.017 \\
(-0.070)\end{array}$ & $\begin{array}{l}0.009 \\
(-0.100)\end{array}$ \\
\hline Satisfaction with healthcare & $\begin{array}{l}-0.004 \\
(-0.040)\end{array}$ & $\begin{array}{l}0.002 \\
(-0.080)\end{array}$ & $\begin{array}{l}0.028 \\
(-0.100)\end{array}$ \\
\hline Overall Satisfaction with standards of living & $\begin{array}{l}-0.020 * * * \\
(-0.040)\end{array}$ & $\begin{array}{l}0.013 \\
(-0.080)\end{array}$ & $\begin{array}{l}0.055^{* *} \\
(-0.100)\end{array}$ \\
\hline Pseudo-R-squared (Conditional) & 0.270 & 0.140 & 0.220 \\
\hline Number of observations & 29,492 & 7732 & 1525 \\
\hline
\end{tabular}

Coefficients are average marginal effects for migration desire, and average conditional marginal effects for migration planning and preparations (decisions). Standard errors are shown in parentheses. Each equation includes country fixed effects

***** Significant at the $0.1 \%$ level

*** Significant at the $1 \%$ level

** Significant at the 5\% level

* Significant at the $10 \%$ level

people are involved in agriculture, the economic activity most attached to land, and consequently less mobile, making it a pull factor that decreases people's desire to leave their areas of residence.
Other individual and household characteristics seemed to significantly influence international migration desire, which was also dependent on marital status, education level and age. Being married was associated with a $4.9 \%$ percentage- 
point lower probability of desiring to migrate, compared to being single. Having post-secondary education was associated with a $5.9 \%$ percentage-point higher probability of intending to migrate, compared to having only elementary education but this probability increased to $7.9 \%$ for those who had obtained tertiary education. In addition, the probability of migration desire decreased by $0.4 \%$ for each year an individual ages.

Social networks seem to play a very influential role in determining international migration desire. Perception of the availability of help from outside the country was associated with a $10.2 \%$ percentage-point higher probability of desiring to migrate, suggesting that access to networks in destination countries was the most influential factor in determining migration desire. This result supports previous research on the importance of migrant diasporas in lowering the information, assimilation, and adaptation costs of potential migration.

\subsection{Migration planning}

In the pool of those desiring to migrate, food insecurity's association with planning to migrate internationally is ambiguous, as shown in the second column of Table 2 . The relationship is positive for those experiencing severe food insecurity and negative for those having moderate food insecurity, but it is statistically insignificant in both cases. Planning to migrate to another country in the following 12 months entails a serious consideration of international migration as a viable option to seek better opportunities. It is different from desiring to migrate in the very sense that it implies dedication to take action to achieve the move. With reference to the conceptual framework detailed in Section 2, this move involves active interaction with the conditioning factors that shape the capacity of people and their access to the resources needed to cover migration costs, which are usually high for international migration. In summary, food insecurity is a determinant of migration desire, but seems to have no clear association with migration planning, an action that is perhaps better explained by other factors.

As the results indicate (in the second column of Table 2), social network effect seems to be the most important determinant of migration planning, the probability of which increases by $12 \%$ due to support from abroad. Planning to migrate entails looking for information on job opportunities, housing, basic rights, and overall life conditions in the potential destinations, all requiring a reliable source of information. In addition, migration is costly and risky, and therefore, the presence of a reliable network in the potential destination is essential in managing and coping with the risks and the uncertainties associated with the eventual migration.

Another determinant factor in planning for international migration is the level of education, which also has a significant role in migration desire. For planning, the results show that having a secondary education would increase the probability of migration planning by $2.1 \%$, compared to those with lower levels of education. The probability further increases to $5.6 \%$ for those having post-secondary education. It is worth noting that the marginal effects of education are greater for migration desire than for migration planning. In the latter case, the marginal effect increases more disproportionately when moving from secondary to post-secondary education. This indicates that the level of education matters more for migration planning than for migration desire. In the case of migration desire, higher education would imply higher ambition to be achieved through migration. However, for migration planning, higher education implies higher capacity to collect information and find opportunities.

\subsection{Migration decision}

Column 3 in Table 2 shows the regression results for the determinants of migration preparations already undertaken for the international move (i.e. migration decision proxy), among those already planning to migrate. They suggest a negative and significant relationship between food insecurity and migration decision. The results present evidence that the level of food insecurity also matters when it comes to deciding to migrate. For example, being moderately food insecure decreases the probability of the decision by $6.9 \%$ compared to those with mild or no food insecurity, but having severe food insecurity decreases this probability by $9.6 \%$.

Several observations emerge from looking comprehensively at Table 2 . There are two variables that are significant for migration desire (the start of decision process) and migration decision (the end of the process) but not for migration planning (the transitional phase). Those with more severe food insecurity are less likely to decide to migrate, as food insecurity is associated with lower access to resources needed to cover migration costs. This is supported by the coefficient of satisfaction with standard of living, which is positively and significantly associated with higher probability to decide to migrate, indicating that those who can migrate and decide to do so are not from the poorest segment of the society. Food insecurity is also positively associated with migration desire, indicating that the more food insecure have higher probability of wanting to move. Furthermore, satisfaction with one's standard of living is negatively associated with migration desire, indicating that those who are less satisfied are more likely to desire to migrate. Note that neither of these variables have strong associations with migration planning.

Age and the presence of support abroad were significant for migration decision, and are the only two factors that are significant determinants in all three stages of the migration process. Age coefficients are negative for migration desire indicating that younger people are more likely to desire to migrate in line with the general literature finding that migrants are younger than non-migrants. However, age coefficients 
become positive for migration planning, which seem to contradict the literature. One possible explanation is that the bulk of the old people was excluded, leaving the sub-samples dominated by younger people. In the pool of these younger people who already desire to migrate, age plays a positive role reflecting higher capacity to overcome constraints to plan and prepare for the move. However, this needs further exploration which is beyond the scope of this paper.

Support from abroad is not only significant for all three steps, but its coefficient increases as we move from desire $(10.2 \%)$ to planning (12\%) to preparations (19\%). It is worth mentioning that, although not revealed by the results, support from abroad may be playing various roles in the process. In the migration desire phase, it is plausible that support from abroad functions as a channel of aspiration where successful stories coming from emigrants may create an incentive to migrate or enhance an existing one, thus strengthening the desire to migrate. In the planning and decision phases, it may become a source of reliable information needed to confront various options needed for concrete migration planning, and it may also represent a security asset on which the potential migrant could count when the migration decision is at stake.

Several variables such as education, area of residence, gender, household income, marital status, employment status and household size, seem to have no significant effect on the decision to migrate, having played a significant role in migration desire, while some of them were significant also in planning, such as education and employment. However, as their signs are similar across the three steps, the sample size, which becomes smaller and smaller once we move further into the decision process, is likely an important factor explaining their lack of significance in the third step. The complexity of migration determinants and the way in which they interact in affecting the decision-making process was highlighted in the conceptual framework (Fig. 1). While the operational model has highlighted solid insights into the role of food insecurity and other factors in shaping peoples' perceptions and actions towards international migration, there may still be a range of other relevant factors that are not captured by the empirical model.

\section{Conclusions and policy implications}

In this paper, we focused on studying the role of food insecurity in the decision processes of peoples in Sub-Sahran Africa to undertake international migration, a topic that is still understudied in the migration literature, which focuses much more on other determinants, such as household income, education, and social networks.

This study contributes in various ways to the migration debate. Using a three-stage conceptual framework that examined individual migration desire, planning and decision, we provide evidence that that the relationship between food insecurity and migration is strong and significant. However, the nature of this relationship depends upon the severity of food insecurity, which reflect the overall economic wellbeing of households and individuals, and on the stage of the migration decision process.

We demonstrate that the relationship between food insecurity and migration desire was positive: food insecurity increased migration desire, and to a greater extent as the severity of food insecurity increased. However, we found that the relationship between migration decision and severe food insecurity was negative. This evidence is in line with the microlevel determinants of the mobility transition and shows that migrants are generally neither the poorest nor the richest segments of a society. The richest do not have the incentive to migrate in the first place, while the poorest, although they have strong incentives to move, are not able to do so due to lack of resources needed to cover necessary migration costs.

Food insecurity is, therefore, an important push factor in the desire to migrate internationally. However, it can serve as a deterrent when it comes to making migration decisions, as food insecurity can make households hesitate to incur expenses associated with migration preparation. The net outcome on migration of worsening food security will depend on the counterbalancing effects of the increasing desire to migrate versus the constraints faced by the food insecure to migration. In this paper we limit ourselves to highlighting that food insecurity is a significant and robust determinant of both desiring to migrate and the final migration decision, but we do not quantify the net outcome. We propose this as an interesting area of potential future work that was beyond the reach of this analysis, and that such an investigation of net effect will entail certain challenges related to two factors: (i) the net impact on migration of food insecurity being small due to the counterbalancing impacts on desire versus the decision to migrate, and (ii) when trying to estimate the determinants of the migration decision directly from the overall population, bias is introduced into the estimates due to the decision to migrate being a rare event in the overall sample (1.5\% of full sample). Addressing these challenges to provide robust estimates of the net impact of food insecurity is the logical next step after having established that food insecurity is indeed a determinant of migration processes in Sub-Saharan Africa.

Even with the limits highlighted, the findings of this paper are still relevant for informing policy, given the recently increased attention to international migration and the worsening global conditions regarding food security. They point to the importance of migration as a fundamental livelihood strategy that households use to hedge against uncertainties and cope with risks, and highlight the fact that it is often not viable for the food insecure. The poorer segments of developing societies do frequently use migration for survival. However, the food insecure, who are the poorest, usually migrate only for short distances as they cannot afford international migration costs. 
Thus, removing migration constraints, including financial ones, could be an effective tool for improving food security.

One policy message that can be drawn from our results is that removing or reducing constraints to migration will benefit the poorest/most food insecure segments of any society, by enabling migration. Bilateral and multi-lateral agreements on trade and economic cooperation, including development aid, should recognize this strong relationship between food insecurity and international migration. They can serve as first platforms to incorporate organized migration schemes across countries that are to the benefits of both potential migrants from lower income countries and the more developed ones, usually in need of agricultural labor even if only seasonally.

\section{Compliance with ethical standards}

Conflict of interest The authors declare that they have no conflict of interest.

\section{Appendix 1: Sensitivity analysis}

We performed a series of robustness and sensitivity tests on the results to examine the possible impact of various macrolevel factors and shocks on the relationship between food insecurity and the migration decision process. Macro-level factors can influence migration decisions in a given country due to the inverse U-shaped relation between a country's level of development and migration as mentioned earlier. Migration rates from poor and rich countries tend to first increase and then decrease with economic development (UNDP 2009). To control for this relationship, we included the UNDP Human Development Index (HDI), which captures three dimensions that are highly pertinent to the level of development: the GDP per capita, life expectancy at birth and the level of education. However, since the relationship between the level of development and migration flows is not linear but rather takes an inverse U-shape, we added HDI-squared to account for this non-linearity.

Some political conditions also matter and may substantially affect the desire, and the subsequent decision, to migrate or to stay. Protracted crises, as mentioned in the conceptual framework, influence migration determinants at all levels. This is the case for fragile and conflict-affected countries where, in addition to direct physical threat, the socio-economic differentials between areas of origin and those of potential destinations start to widen dramatically. In addition, crises reduce opportunities and worsen services in the area of origin. As a consequence of the impacts of the crises on migration determinants, the pool of potential migrants (those desiring to migrate) increases, and ultimately, migration outflows increase as well (FAO 2018). We used the data from FAO et al. (2017) to classify the countries in question into countries facing crises or otherwise using a binary variable.

Table 3 show the results of the sensitivity analysis. We first tested the results by adding only HDI and HDI_squared (columns 1), then we tested by adding only the conflict dummy (columns 2). Lastly, we tested the model by adding both macro variables, i.e. HDI, HDI squared and the conflict dummy (columns 3). The results show that including these macrolevel control variables did not alter the relationship between food insecurity and migration.

Therefore, in all robustness and sensitivity checks, we found that the relationship between food insecurity and migration behavior was robust. The magnitude and significance of the food insecurity coefficients remained within a very narrow range. Consequently, the results regarding the role of

Table 3 Effects of macro level factors

\begin{tabular}{|c|c|c|c|c|c|c|c|c|c|}
\hline & \multicolumn{3}{|c|}{ Migration desire } & \multicolumn{3}{|c|}{ Migration planning } & \multicolumn{3}{|c|}{ Migration decision } \\
\hline & (1) & $(2)$ & (3) & (1) & $(2)$ & (3) & (1) & $(2)$ & (3) \\
\hline Moderate Food insecurity & $\begin{array}{l}0.039 * * * \\
(0.05)\end{array}$ & $\begin{array}{l}0.039 * * * \\
(0.05)\end{array}$ & $\begin{array}{l}0.038 * * * \\
(0.05)\end{array}$ & $\begin{array}{l}-0.013 \\
(0.1)\end{array}$ & $\begin{array}{l}-0.014 \\
(0.1)\end{array}$ & $\begin{array}{l}-0.013 \\
(0.09)\end{array}$ & $\begin{array}{l}-0.071 \\
(0.2)\end{array}$ & $\begin{array}{l}-0.069 \\
(0.2)\end{array}$ & $\begin{array}{l}-0.074 * \\
(0.2)\end{array}$ \\
\hline Severe Food insecurity & $\begin{array}{l}0.052 * * * \\
(0.06)\end{array}$ & $\begin{array}{l}0.052 * * * \\
(0.06)\end{array}$ & $\begin{array}{l}0.052 * * * \\
(0.06)\end{array}$ & $\begin{array}{l}0.017 \\
(0.1)\end{array}$ & $\begin{array}{l}0.016 \\
(0.1)\end{array}$ & $\begin{array}{l}0.018 \\
(0.09)\end{array}$ & $\begin{array}{l}-0.1^{*} \\
(0.2)\end{array}$ & $\begin{array}{l}-0.1^{*} \\
(0.2)\end{array}$ & $\begin{array}{l}-0.1 * * \\
(0.2)\end{array}$ \\
\hline Support from abroad & $\begin{array}{l}0.1 * * * \\
(0.04)\end{array}$ & $\begin{array}{l}0.1 * * * \\
(0.04)\end{array}$ & $\begin{array}{l}0.1 * * * \\
(0.04)\end{array}$ & $\begin{array}{l}0.1 * * * \\
(0.09)\end{array}$ & $\begin{array}{l}0.1 * * * \\
(0.09)\end{array}$ & $\begin{array}{l}0.1 * * * \\
(0.07)\end{array}$ & $\begin{array}{l}0.2^{* * * *} \\
(0.2)\end{array}$ & $\begin{array}{l}0.2 * * * \\
(0.2)\end{array}$ & $\begin{array}{l}0.1 * * * \\
(0.2)\end{array}$ \\
\hline HDI & $\begin{array}{l}0.4 \\
(9.1)\end{array}$ & & $\begin{array}{l}0.78 \\
(9.3)\end{array}$ & $\begin{array}{l}-2.04 \\
(9.3)\end{array}$ & & $\begin{array}{l}-2.1 \\
(11)\end{array}$ & $\begin{array}{l}4.3 \\
(0.1)\end{array}$ & & $\begin{array}{l}5.4 * * \\
(9.4)\end{array}$ \\
\hline HDI squared & $\begin{array}{l}-0.4 \\
(8.1)\end{array}$ & & $\begin{array}{l}-0.68 \\
(8.2)\end{array}$ & $\begin{array}{l}1.5 \\
(8.3)\end{array}$ & & $\begin{array}{l}1.6 \\
(9.8)\end{array}$ & $\begin{array}{l}-3.5 \\
(9.9)\end{array}$ & & $\begin{array}{l}-4.3 * * \\
(8.3)\end{array}$ \\
\hline Conflict & & $\begin{array}{l}0.02 \\
(0.2)\end{array}$ & $\begin{array}{l}0.03 \\
(0.25)\end{array}$ & & $\begin{array}{l}0.03 \\
(0.3)\end{array}$ & $\begin{array}{l}-0.01 \\
(0.2)\end{array}$ & & $\begin{array}{l}0.01 \\
(0.3)\end{array}$ & $\begin{array}{l}0.09 * \\
(0.2)\end{array}$ \\
\hline
\end{tabular}

*** Significant at the $1 \%$ level

** Significant at the $5 \%$ level

* Significant at the $10 \%$ level 
food insecurity in the migration decision process can be claimed to be robust across model specifications and samples.

\section{Appendix 2: Tests of multicollinearity}

We tested for potential multi-collinearity between the explanatory variables in the three regressions using Variance Inflation Factors (VIF). Results of the test are reported in Table 4. This index quantifies the extent of correlation between any explanatory variable with other explanatory variables in a model. Higher values indicate that it is difficult and sometimes impossible to assess accurately the contribution of the relevant explanatory variable in predicting the dependent variable. In our model, only the age variables (age and age squared) have high degrees of multi-collinearity, but only in the full sample which was the one which was used to assess migration desire. The fact that they were the only two variables with high VIF means that age and age-squared are correlated with each other but not with any of the other explanatory variables. Therefore, we tested the model again by rerunning the regression for migration desire after dropping the variables age and age squared from the explanatory variables. No significant changes occurred due to omitting these two variables (Table 5).

Table 4 Variance inflation factors for the explanatory variables of the three logit regressions

\begin{tabular}{llll}
\hline Variables & $\begin{array}{l}\text { Migration } \\
\text { desire }\end{array}$ & $\begin{array}{l}\text { Migration } \\
\text { planning }\end{array}$ & $\begin{array}{l}\text { Migration } \\
\text { decision }\end{array}$ \\
\hline FIES & 1.2 & 1.2 & 1.2 \\
Residence & 1.1 & 1.1 & 1.1 \\
Age & 29.2 & 1.3 & 1.3 \\
Age squared & 27.5 & 1 & 1.0 \\
Gender & 1.1 & 1.1 & 1.1 \\
Log household income & 1.6 & 1.6 & 1.6 \\
Married or domestic partner & 1.4 & 1.4 & 1.4 \\
Employ & 1.2 & 1.1 & 1.1 \\
Number of children & 1.1 & 1.6 & 1.7 \\
Number of adults & 1.1 & 1.1 & 1.2 \\
Household size & 1.3 & 1.7 & 1.9 \\
Education & 1.2 & 1.2 & 1.2 \\
Importance of religion & 1.0 & 1.01 & 1.0 \\
Support from abroad & 1.1 & 1.1 & 1.0 \\
Internet access & 1.0 & 1.0 & 1.0 \\
Satisfaction with education system & 1.2 & 1.2 & 1.3 \\
Satisfaction with access to water & 1.1 & 1.1 & 1.2 \\
Overall satisfaction with city or & 1.2 & 1.2 & 1.2 \\
$\quad$ area of residence & 1.2 & 1.3 & 1.3 \\
Satisfaction with healthcare & 1.2 & 1.3 & 1.2 \\
Overall Satisfaction with standards & & & \\
$\quad$ of living & & & \\
\hline & & & \\
\hline
\end{tabular}

Table 5 Average marginal effects from the binary-choice econometric equation of migration desire after dropping age and age squared as explanatory variables

\begin{tabular}{ll}
\hline Variables & Marginal effect \\
\hline Severe food insecurity & $0.044^{* * * * *}$ \\
moderate food insecurity & $0.036^{* * * *}$ \\
Residence & $-0.049^{* * * *}$ \\
Gender & $0.049^{* * * *}$ \\
Log household income & $0.014^{*}$ \\
Married or domestic partner & $-0.105^{* * * *}$ \\
Employed part time & $0.024^{* * *}$ \\
Employed full time & $0.077^{* * * *}$ \\
Number of children & -0.002 \\
Number of adults & 0.003 \\
Household size & $0.006^{* * * *}$ \\
Secondary education & $0.097^{* * * *}$ \\
Post-secondary education & $0.093^{* * * *}$ \\
Importance of religion & -0.012 \\
Support from abroad & $0.103^{* * * *}$ \\
Internet access & $0.024^{* *}$ \\
Satisfaction with education system & $-0.021^{* * *}$ \\
Satisfaction with access to water & -0.008 \\
Overall satisfaction with city or area of residence & $-0.108^{* * * * *}$ \\
Satisfaction with healthcare & -0.004 \\
Overall Satisfaction with standards of living & -0.012 \\
\hline
\end{tabular}

**** Significant at the $0.1 \%$ level

*** Significant at the $1 \%$ level

** Significant at the $5 \%$ level

* Significant at the $10 \%$ level

The views expressed in this publication are those of the author(s) and do not necessarily reflect the views or policies of FAO.

Open Access This article is licensed under the terms of the Creative Commons Attribution-NonCommercial-ShareAlike 3.0 IGO License, which permits any non-commercial use, sharing, adaptation, distribution and reproduction in any medium or format, as long as you give appropriate credit to the Food and Agriculture Organization of the United Nations (FAO), provide a link to the Creative Commons licence, and indicate if changes were made. If you remix, transform, or build upon this article or a part thereof, you must distribute your contributions under the same licence as the original. The use of the Food and Agriculture Organization of the United Nations (FAO)'s name, and the use of the Food and Agriculture Organization of the United Nations (FAO)'s logo, shall be subject to a separate written licence agreement between the Food and Agriculture Organization of the United Nations (FAO) and the user and is not authorized as part of this CC-IGO licence. Note that the link provided above includes additional terms and conditions of the licence.

The images or other third party material in this article are included in the article's Creative Commons licence, unless indicated otherwise in a credit line to the material. If material is not included in the article's Creative Commons licence and your intended use is not permitted by statutory regulation or exceeds the permitted use, you will need to obtain permission directly from the copyright holder.

To view a copy of this licence, visit http://creativecommons.org/licenses/ by-nc-sa/3.0/igo/. 


\section{References}

Beine, M., Docquier, F., \& Özden, Ç. (2011). Diasporas. Journal of Development Economics, 95(1), 30-41.

Borjas, G. (1987). Self-selection and the earnings of immigrants. American Economic Review, 77(4), 531-553.

Chiquiar, D., \& Hanson, G. H. (2005). International migration, self-selection, and the distribution of wages: Evidence from Mexico and the United States. Journal of Political Economy, 113(2), 239-281.

Chiswick, B. (1999). Are immigrants favorably self-selected? American Economic Review, 89(2), 181-185.

Clemens, M. (2011). Economics and emigration: Trillion-dollar bills on the sidewalk? Journal of Economic Perspectives, 25(3), 83-106.

Clemens, M. (2014). Does development reduce migration? In R. Lucas (Ed.), International handbook on migration and economic development (Chap. 6, pp.152-185). London: Edward Elgar.

Coates, J., Wilde, P. E., Webb, B., Rogers, L., \& Houser, R. F. (2006). Comparison of a qualitative and a quantitative approach to developing a household food insecurity scale for Bangladesh. Journal of Nutrition, 136, 1420S-1430S.

Crush, J. 2012. Migration, Development and Urban Food Security. Urban Food Security Series No. 9. Kingston and Cape Town, Queen's University and African Food Security Network (AFSUN).

Docquier, F., Peri, G., \& Ruyssen, I. (2014). The cross-country determinants of potential and actual migration. International Migration Review, 48(S1), S37-S99.

FAO. 2016. Methods for estimating comparable rates of food insecurity experienced by adults throughout the world. Rome, FAO.

FAO. 2018. The state of food and agriculture 2018. Migration, agriculture and rural development. Rome. FAO.

FAO, IFAD, UNICEF, WFP and WHO. 2017. The state of food security and nutrition in the world 2017. Building resilience for peace and food security. Rome, FAO.

FAO, IFAD, UNICEF, WFP and WHO. 2018. The state of food security and nutrition in the world 2018. Building climate resilience for food security and nutrition. Rome, FAO.

Gallup (2018). Worldwide research: methodology and codebook. Gallup World Poll. $81 \mathrm{pp}$

IADB, IFAD, IOM, OAS \& WFP. 2017. Food security and emigration. Why people flee and the impact on family members left behind in El Salvador, Guatemala and Honduras. Rome, WFP.

Mayda, A. M. (2010). International migration: A panel data analysis of the determinants of bilateral ows. Journal of Population Economics, 23(4), 1249-1274.

Mercandalli, S. \& Losch, B. (Eds.). (2017). Rural Africa in motion. Dynamics and drivers of migration south of the Sahara. Rome: FAO and CIRAD. 60 pp. (also available at http://www.fao.org/3/ I7951EN/i7951en.pdf).

Nord, M., Cafiero, C., \& Viviani, S. (2016). Methods for estimating comparable prevalence rates of food insecurity experienced by adults in 147 countries and areas. Journal of Physics: Conference Series, 772(1), 012060 IOP Publishing.

Ortega, F., \& Peri, G. (2013). The effect of income and immigration policies on international migrations. Migration Studies, 1(1), $1-28$

Plaza, S., Navarette, M., \& Ratha, D. (2011). Migration and remittances household surveys: Methodological issues and new findings from sub-Saharan Africa. Washington DC: World Bank.
Rademacher-Schulz, C., Schraven, B., \& Mahama, E. S. (2014). Time matters: Shifting seasonal migration in northern Ghana due to rainfall variability and food insecurity. Climate and Development, 6(1), 46-52.

Radimer, K. L. (2002). Measurement of household food security in the USA and other industrialized countries. Public Health Nutrition, 5(6A), 859-864.

Radimer, K. L., Olson, C. M., \& Campbell, C. C. (1990). Development of indicators to assess hunger. Journal of Nutrition, 120(Suppl (11)), $1544-1548$.

Radimer, K. L., Olson, C. M., Greene, J. C., Campbell, C. C., \& Habicht, J. P. (1992). Understanding hunger and developing indicators to assess it in women and children. Journal of Nutrition Education, 24(Suppl), 36-45.

Rasch, G. (1960). Probabilistic models for some intelligence and attainment tests. Copenhagen: Danish Institute for Educational Research.

Schultz, T. (1961). Investment in human capital. American Economic Review, 51(1), 1-17.

Sjaastad, L. (1962). The costs and returns of human migration. Journal of Political Economy, 70(5), 8093.

Smith, D.M., \& Floro, M.S. (2017). Food insecurity, gender and international migration. UNU-WIDER, Migration and Mobility, Conference Proceedings. Accra, Ghana, October 5, 2017.

UNDP, 2009. Human development report 2009: Overcoming barriers: Human mobility and development. The United Nations Development Programme.

Warner, K., \& Afifi, T. (2014). Where the rain falls: Evidence from 8 countries on how vulnerable households use migration to manage the risk of rainfall variability and food insecurity. Climate and Development, 6(1), 1-17.

Zezza, A., Carletto, C., Davis, B., \& Winters, P. (2011). Assessing the impact of migration on food and nutrition security. Food Policy, $36(1), 1-6$.

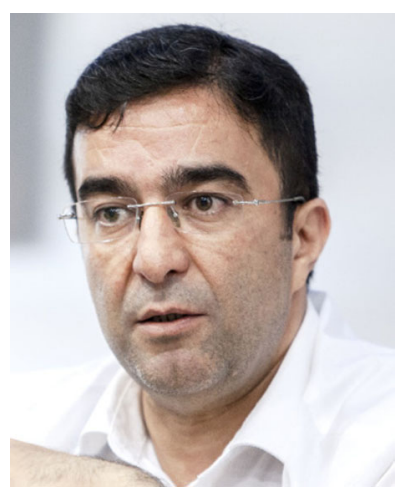

Ahmad Sadiddin is an economist at the Food and Agriculture Organization of the United Nations (FAO). He holds a bachelor degree in agricultural engineering from Al-Bath University (Syria), MSc in agricultural Economics from the University of London and Ph.D. in agricultural economics and policy from the University of Naples Federico II. Working for the Syrian government, University of Florence and the FAO, he has contributed to a wide range of studies since 2003, including topics such as farming systems, water economics and comparative advantages of agricultural value chains. His recent research interests have focused on economics of food systems, rural and structural transformations and the economics of migration. 


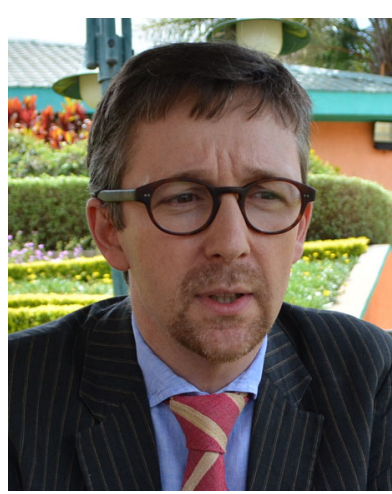

Dr. Andrea Cattaneo is a Senior Economist at FAO, leading the team that produces The State of Food and Agriculture, which is FAO's flagship publication. He has 25 years of experience in examining economic issues relating to development, food security, and climate change. In recent years his focus has been on migration and on the role of rural-urban linkages in rural transformation. $\mathrm{He}$ previously held positions at the International Food Policy Research Institute (IFPRI), the Economic Research Service (ERS) of the U.S. Department of Agriculture, the Organisation for Economic Co-operation and Development (OECD), and the Woods Hole Research Center. Dr. Cattaneo has an extensive publication record in peer-reviewed journals spanning a range of topics. He has analyzed the welfare impacts of free trade agreements, written on issues of food security and barriers to innovation, designed innovative economic mechanisms for environmental programs, and studied the role of risk and uncertainty under climate change.

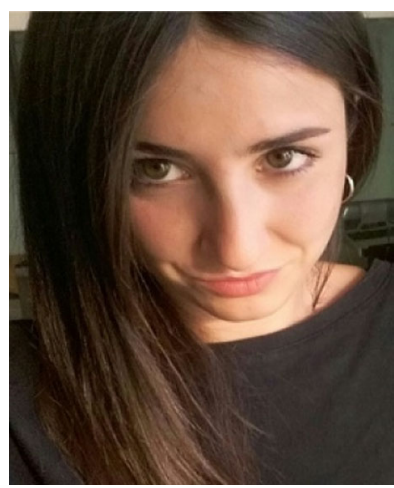

Marinella Cirillo is a consultant at the Food and Agriculture organization of the United Nations (FAO) in the Food Security and Nutrition Statistics Team, where she contributes to the statistical and economic analysis and researches on food security issues, particularly concerning the Food Insecurity Experience Scale (FIES). Marinella obtained a University degree in International Economics at Université Paris 1 SorbonnePanthéon in France and she is currently in her first year of a $\mathrm{PhD}$ in Economic Geography studies at Universitá La Sapienza in Rome. Thanks to her economic and statistic solid background, she has experience in food security, economic development and migration researches.

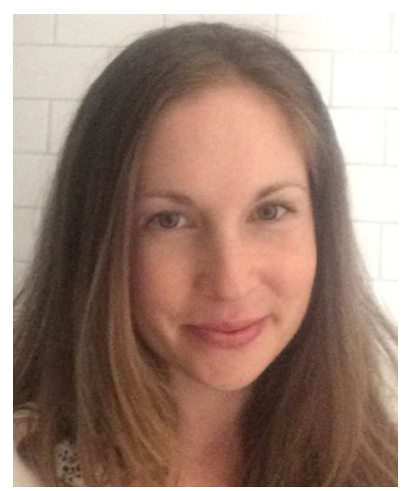

Meghan Miller is a consultant at the Food and Agriculture Organization of the United Nations (FAO) and a graduate student at McGill University. She holds a Bachelor's degree from Cornell University in Biology and Society, specialising in International Relations, and a Master's degree in Human Nutrition from McGill University. She has been involved in work on experience-based food security measurement since 2005 , specifically the Food Insecurity Experience Scale (FIES) in recent years. Her main research interests are the social drivers and consequences of food insecurity, particularly the role of social support. She is currently enrolled in the McGill University School of Social Work, where she is studying social policy and public services in relation to food security. 